\title{
Energy-water optimization model incorporating rooftop water harvesting for lawn irrigation
}

\author{
Evan M. Wanjiru*, Xiaohua Xia \\ Centre of New Energy Systems, Department of Electrical, Electronic and Computer Engineering, University of \\ Pretoria, Pretoria 0002, South Africa
}

\begin{abstract}
The management of energy and water is increasingly gaining attention among domestic end-users. In developing countries, potable water supply is unreliable leading to alternative strategies such as rooftop water harvesting (RWH), storage and pumping. Since urban garden irrigation is the highest outdoor water consumer, optimal scheduling is important to conserve energy and water over conventional lawn irrigation methods. A model to optimally control the lawn irrigation was developed with the simulation results showing $17.4 \%$ potential water savings when using water directly from municipal sources. With RWH of a 1-hr event with 1-mm rainfall from a $120-\mathrm{m}^{2}$ roof, the model can potentially save $23.4 \%$ of water and $73.8 \%$ in energy costs per day. Such savings are important in reducing the demand for existing water and energy sources as well as greenhouse emissions. Further, this paper looks into two strategies to maximize the pump's life through minimizing the maintenance cost.
\end{abstract}

Keywords: buildings, energy, optimal scheduling, rooftop water harvesting, time-of-use tariff, water

\begin{tabular}{|ll|}
\hline \multicolumn{2}{|l|}{ Nomenclature } \\
$A_{\text {lawn }}$ & Area of the lawn $\left(\mathrm{m}^{2}\right)$ \\
$A_{r t}$ & Area of the building's rooftop $\left(\mathrm{m}^{2}\right)$ \\
$A_{\text {tank }}$ & Cross-sectional area of the tank $\left(\mathrm{m}^{2}\right)$ \\
$D_{r}$ & Water drainage in the lawn $(\mathrm{m})$ \\
$E T_{0}, E T_{c}$ & Reference and crop evapotranspiration $(\mathrm{m})$ \\
$F C$ & Field capacity $\left(\mathrm{m}^{3}\right.$ of water $/ \mathrm{m}^{3}$ of soil) \\
$I$ & Irrigation amount applied to the lawn $(\mathrm{m})$ \\
$J$ & Objective function (currency) \\
$K_{c}$ & Crop coefficient \\
$M A D$ & Maximum allowable depletion $(\%)$ \\
$N$ & Total number of samples during the control horizon \\
\hline
\end{tabular}

*Corresponding author. Tel. +27 12420 6767; Fax +27 123625000.

Email address: murimev@gmail.com (Evan M. Wanjiru ) 


\begin{tabular}{|ll|}
\hline$P$ & Precipitation $(m)$ \\
$p_{e}$ & Price of electricity using TOU tariff $($ currency $/ k W h)$ \\
$p_{m}$ & Pump's motor rating $(k W)$ \\
$p_{w}$ & Price of water $\left(\right.$ currency $\left./ m^{3}\right)$ \\
$P W P$ & Permanent wilting point $\left(m^{3}\right.$ of water $/ m^{3}$ of soil) \\
$Q_{(1,2)}$ & Amount of water in one sampling interval $\left(m^{3}\right)$ \\
$R A W$ & Readily available water $(m)$ \\
$R_{o}$ & Run-off of water from the lawn $(m)$ \\
RWH & Rooftop water harvesting \\
$R_{z}$ & Root zone depth $(m)$ \\
$S$ & Amount of water in the soil $(m)$ \\
$S_{A W}$ & Water in the root zone available to the plant $(m)$ \\
TOU & Time-of-use tariff \\
$t_{o}, t_{f}$ & Time in the first and final samples respectively \\
$t_{s}$ and $j$ & Sampling period $(h)$ and $j^{t h}$ sampling interval \\
$u_{1}, u_{2}$ & State of the solenoid valve and pump switches respectively \\
$V_{l}, V_{u}$ & Minimum and maximum water volume in the tank $\left(m^{3}\right)$ \\
& \\
Rand(R) & South African currency $((1$ Rand = 0.081 USD), as at 01 June 2015) \\
\hline
\end{tabular}

\section{Introduction}

Water and energy are vital resources for human for survival facing immense challenges [1, 2]. Existing potable water supplies are fast reaching their limit whereas water demand is rapidly increasing [3]. Worse still, rapid urbanization is increasing the strain to the water and electricity utilities especially in developing nations [4, 5], like South Africa, which is a water-scarce country [6]. In reality, the demand for both potable water and energy in South Africa far outweighs the supply [7, 8].

The Water-energy nexus is receiving increased attention [9]. However, domestic consumers are hardly aware of the direct and indirect benefits of the water-energy nexus savings at home [10], such as; energy savings for purifying water, utility pumping and corresponding $\mathrm{CO}_{2}$ reduction [11], energy savings from the waste water purification and lower cost for potable water and waste water management [12]. Whilst most research in South Africa has concentrated on energy efficiency [13, 14, 15] and electrical demand side management [16, 17, 18], little attention has been given to water demand management and its effect on energy consumption [19, 20].

According to the Department of Water Affairs and Forestry (DWAF), although there is no consolidated database of information for water use from water utilities in South Africa, the national urban household water use is roughly estimated at $50 \%$ of the total water demand [21]. The outdoor water demand, mainly garden irrigation for those households with urban gardens [22], is estimated to contribute $40-60 \%$ of the total household water demand [23]. Therefore, by increasing the efficiency of gardening water use, the consumption can be reduced by $6 \%$ to $30 \%$ of the total 
gardening water use ${ }^{1}$. The potential means of reducing this amount are: using water-wise plants, mulching, efficient irrigation systems, irrigation scheduling, rain water harvesting and recycling waste water [21].

Research on irrigation scheduling in urban lawns has mainly concentrated on water conservation while rooftop water harvesting $(\mathrm{RWH})$ of rain water has concentrated on making the water safe and reliable to the rural areas of South Africa [24, 25]. However, another benefit of RWH is improving water quality through runoff reduction [26]. Evapotranspiration based controllers are superior to time-based controllers in irrigation scheduling [27]. However, in case of precipitation, they are programmed by the manufacturers to pause for a certain period of days before resuming irrigation irrespective of whether the precipitation was sufficient or not [28]. In addition, the scheduling considered so far makes use of water solely from the utility [29]. Bocanegra-Martínez et.al. [30] designed an optimal rainwater collecting system in residential areas and showed its viability to use to meet certain residential water demands. However, the model was not optimized to specific end uses.

This paper reports the first attempt to design a practical and economically attractive optimal irrigation scheduling model using the harvested rain water and the TOU electricity price tariff. The harvested water from the rooftop is stored in a reservoir which only gets the potable utility water whenever the stored water has been depleted through the irrigation scheduling. There has been several studies seeking to address the reliability of RWH systems meant for supplying water to various demands like lawn irrigation and toilet flushing using solely the harvested water [31, 32]. The municipal water sources are used as a back up to improve the reliability of the system and ensure that the tank never runs dry. Further, optimal control strategy has the ability to predict the dynamics of water in the tank effectively minimizing the chance of spillage taking place. This paper presents an optimal scheduling breakthrough that can reduce both water and energy consumption leading towards achieving more sustainable buildings. Furthermore, the optimal model with RWH is useful in developing the nations' cities where utility potable water is unreliable due to the high demand that surpasses the existing supply infrastructure. This optimal model, if widely adopted, would reduce the demand for potable water and energy from the utilities, lower waste water drainage and purification cost and at the same time lowering the bills associated with both resources.

\section{Model layout and formulation}

\subsection{Schematic model layout}

The first model constitutes the sprinkler directly connected to the utility water as schematically shown in figure 1. In this case, the irrigation is controlled using the utility switch $u_{1}$.

The schematic layout of the model for RWH system is shown in figure 2. When the rain falls on the rooftop of a house, it is directed and stored in a tank reservoir placed on the ground. However, since it only rains for a certain period, the tank is also fed by utility water to supplement the harvested water if the stored water nears depletion and there is demand from the lawn vegetation.

\footnotetext{
${ }^{1}$ Water conservation and water demand management www.dwa.gov.za
} 


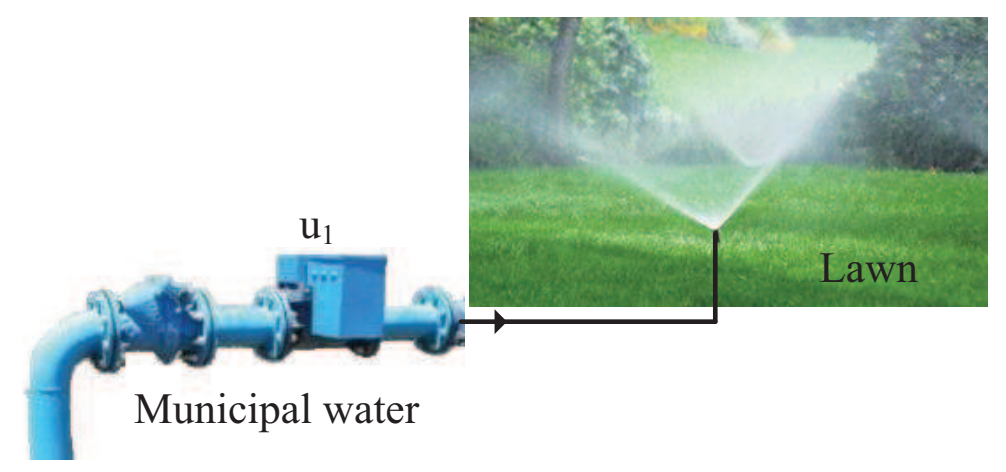

Figure 1: Schematic of directly connected irrigation

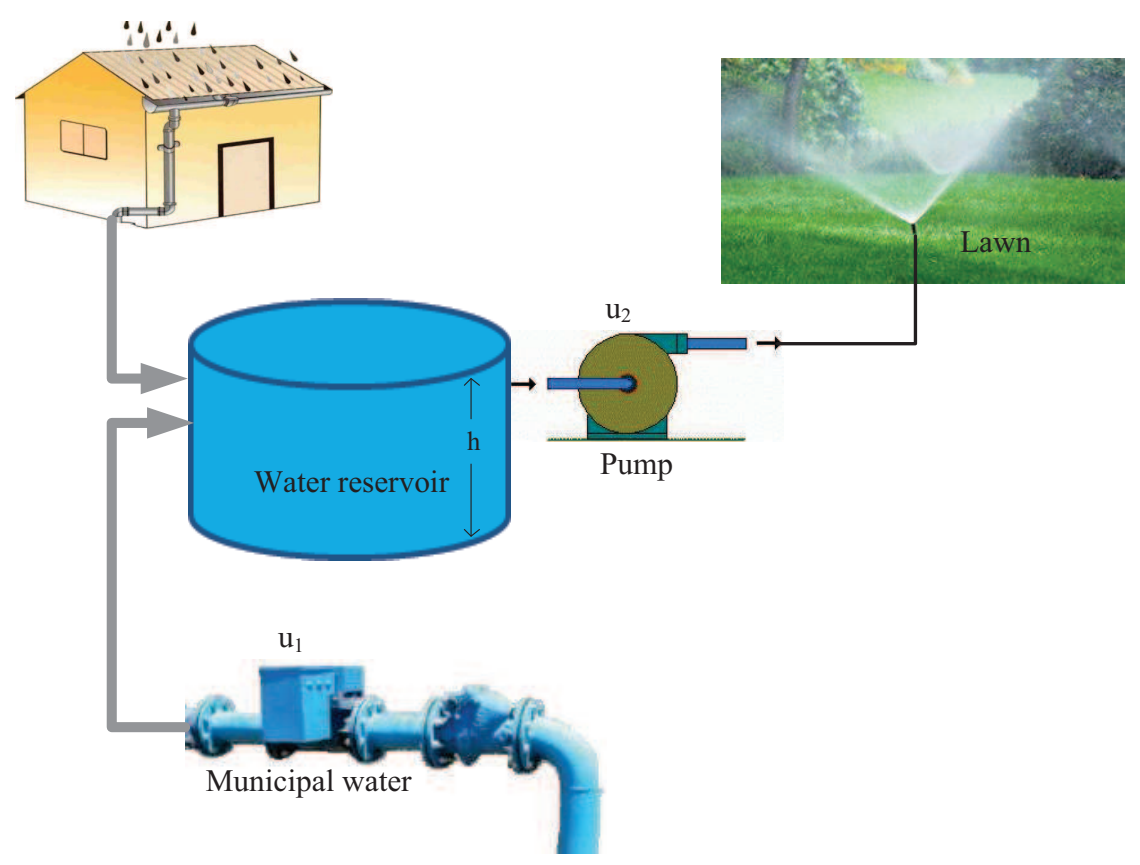

Figure 2: Schematic of RWH for lawn irrigation

The main operational energy consumption for RWH systems come from ultraviolet (UV) disinfection and pumping water from the tank to the end use [33]. Only the pumping energy is considered in this paper as the intended water use doesn't require treatment but has low flow rate and head. The energy consumed by this pump is a function of the water consumed by the end uses it supplies [34]. Here, both the tank filling with municipal water and irrigation are controlled through switch $u_{1}$ and pump switch $u_{2}$.

\subsection{Model for optimal scheduling without rooftop water harvesting}

The model involves scheduling for lawn irrigation making use of the utility water directly assuming that the water is always reliable and has the correct flow rate and feed to operate the sprinklers. 


\subsubsection{Objective function}

The objective in this model is to minimize the cost of the water used to irrigate the lawn in order to maintain the water level in the soil within the required limits over the given control horizon [35]. In this paper, we consider an evaluation period of one day, or a full operation cycle of 24 hours, from 0 to hour 24 with a sampling period, $t_{s}$, of 15 minutes. This leads to a total number of samples $N=\frac{24}{t_{s}}=96$. Hence, the objective function, $J$, is,

$$
J=\sum_{j=1}^{N} p_{w} Q_{1} u_{1}(j)
$$

where $Q_{1}\left(\mathrm{~m}^{3}\right)$ is the volume of utility water flowing in a sampling interval, $p_{w}\left(R / \mathrm{m}^{3}\right)$ is the cost of water charged by the water utility and $u_{1}$ is the state of the solenoid valve used to switch on or off the flow of the water to irrigation. It is a binary control variable that assumes the values of 0 or 1 representing off or on states respectively. The authors acknowledge that $Q_{1}$ maybe practically variable. However, due to its complexity, we have, in this introductory work, assumed that it is constant.

\subsubsection{Constraints}

These are the limits that affect the operation of the irrigation system.

\section{A Soil water balance}

The FAO-56 Penman-Monteith equation is the standard technique for obtaining reference evapotranspiration, $E T_{0}$, whose data is obtained from weather stations ${ }^{2}$. Crop evapotranspiration, $E T_{c}$, obtained from $E T_{0}$, results from the various water inefficiencies in various crops [36]. It is obtained as

$$
E T_{c}=K_{c} E T_{0}
$$

where $K_{c}$ is the crop coefficient. Irrigation scheduling is meant to ensure that the soil doesn't dry beyond a certain threshold [29]. The amount of water held in the root zone available to the plant, $S_{A W}$ in $(m)$, is

$$
S_{A W}=(F C-P W P) \times R_{z}
$$

where $F C$ (volume \%) is the field capacity, $P W P($ volume \%) is the permanent wilting point and $R_{z}(m)$ is the plant root zone. The amount of water allowed to leave the root zone without causing plant stress is the readily available water, $R A W(m)$, [37]. Irrigation should be applied when the water level drops by a percentage known as the maximum allowable depletion, MAD (\%), which is the amount of water relatively easily extracted by plant without causing plant stress [28]. The two quantities are related as follows:

$$
R A W=S_{A W} \times M A D
$$

\footnotetext{
${ }^{2}$ Crop evapotranspiration - Guidelines for computing crop water requirements www.fao.org/docrep/x0490e/ $\mathrm{x} 0490 \mathrm{e} 00 . \mathrm{htm}$
} 
This means that the amount of water that can be extracted from the soil by the plant, $S(m)$ is such that

$$
(F C-R A W) \leq S \leq F C
$$

The plant water extraction then leads to a water balance such that

$$
S=I+P-E T_{c}-R_{o}-D_{r}
$$

In this equation, all units are $(m)$. Irrigation $(I)$ aims to match the crop evapotranspiration $\left(E T_{c}\right)$ losses and precipitation $(P)$ added by adding sufficient water in order to maintain the water content within the acceptable range. In this paper, the precipitation mainly considered is rainfall. Therefore, the run-off, $R_{o}$, and drainage, $D_{r}$, are assumed to be negligible [29] making equation (6) to,

$$
S=I+P-E T_{c}
$$

The dynamics of the amount of water in the soil can be expressed in discrete-time domain by a first order difference equation as follows:

$$
S(j)=S(j-1)+I(j)+P(j)-E T_{c}(j), \quad(1 \leq j \leq N)
$$

But irrigation is provided through pumping the water. Therefore, the above equation can be rewritten as

$$
S(j)=S(j-1)+\frac{Q_{1}}{A_{\text {lawn }}} u_{1}(j)+P(j)-E T_{c}(j), \quad(1 \leq j \leq N)
$$

where $A_{\text {lawn }}$ is the top area of the lawn being irrigated $\left(\mathrm{m}^{2}\right)$. The amount of water in one sampling interval, $Q_{1}$, is assumed as constant throughout the control horizon. Therefore, only the status of the solenoid valve, $u_{1}$, is the control variable. Therefore, by recurrence manipulation, the amount of water in the soil at the $j^{\text {th }}$ sampling interval can be expressed in terms of the initial amount of water in the soil $S(0)$ as follows,

$$
S(j)=S(0)+\sum_{i=1}^{j}\left(\frac{Q_{1}}{A_{\text {lawn }}} u_{1}(i)+P(i)-E T_{c}(i)\right), \quad(1 \leq j \leq N)
$$

The water content must not exceed the $F C$ and not allow more depletion than the MAD. By letting $d_{l}(m)=F C-R A W$ and $d_{u}(m)=R A W$, inequality (5) can be expressed as,

$$
d_{l} \leq S(0)+\sum_{i=1}^{j}\left(\frac{Q_{1}}{A_{\text {lawn }}} u_{1}(i)+P(i)-E T_{c}(i)\right) \leq d_{u}, \quad(1 \leq j \leq N)
$$

where $d_{l}(m)$ and $d_{u}(m)$ are the lower and upper allowable depth of water in the soil respectively.

\section{$B$ Watering restriction}

High solar illumination coupled with water scarcity in South Africa has made some water utilities to ban garden watering between 11:00-15:00 hours ${ }^{3}$ since most of the water would be lost to the

\footnotetext{
${ }^{3}$ Umhlathuze Local Municipality Water Services By-laws 2010 www . umhlathuze.gov .za
} 
high evaporation. This is modeled as below.

$$
u_{1}(i)=0 \quad \forall i \in\left[\frac{11}{t_{s}}, \frac{15}{t_{s}}\right]
$$

\section{Boundaries}

The utility water switch is bounded between 0 and 1 representing off and on status respectively.

$$
0 \leq u_{1}(j) \leq 1 \quad(1 \leq j \leq N)
$$

\subsubsection{Algorithm}

The generalized optimization formulation of a linear problem is to minimize $f^{T} X$ subject to inequality constraints $(A X \leq b)$, equality constraints $\left(A_{e q} X=b_{e q}\right)$ and the upper and lower bounds of the control variable $\left(L_{B} \leq X \leq U_{B}\right)$ [38]. Vector $X$ contains the variables being controlled, where in this case, it contains the status of the solenoid valve controlling the irrigation events using the municipal water. $A$ and $A_{e q}$ are matrices while $f, b, L_{B}$ and $U_{B}$ are vectors which are obtained as follows.

$$
X=\left[\begin{array}{lllll}
u_{1}(1) & u_{1}(2) & u_{1}(3) & \ldots & u_{1}(N)
\end{array}\right]_{N \times 1}^{T}
$$

and from objective function (1),

$$
f^{T}=\left[\begin{array}{llll}
p_{w} Q_{1} & p_{w} Q_{1} & \ldots & p_{w} Q_{1}
\end{array}\right]_{1 \times N}
$$

If we denote

$$
\begin{gathered}
A_{1}=\left[\begin{array}{cccc}
-\frac{Q_{1}}{A_{\text {lawn }}} & 0 & \ldots & 0 \\
-\frac{Q_{1}}{A_{\text {lawn }}} & -\frac{Q_{1}}{A_{\text {lawn }}} & \ldots & 0 \\
\vdots & \vdots & \ddots & \vdots \\
-\frac{Q_{1}}{A_{\text {lawn }}} & -\frac{Q_{1}}{A_{\text {lawn }}} & \ldots & -\frac{Q_{1}}{A_{\text {lawn }}}
\end{array}\right]_{N \times N} \\
b_{1}=\left[\begin{array}{c}
-d_{l}+S(0)+P(1)-E T_{c}(1) \\
-d_{l}+S(0)+(P(1)+P(2))-\left(E T_{c}(1)+E T_{c}(2)\right) \\
\vdots \\
-d_{l}+S(0)+(P(1)+\ldots+P(N))-\left(E T_{c}(1)+\ldots+E T_{c}(N)\right)
\end{array}\right]_{N \times 1} \\
b_{2}=\left[\begin{array}{c}
d_{u}-S(0)-P(1)+E T_{c}(1) \\
d_{u}-S(0)-(P(1)+P(2))+\left(E T_{c}(1)+E T_{c}(2)\right) \\
\vdots \\
\left.d_{u}-S(0)-(P(1))+\ldots+P(N)\right)+\left(E T_{c}(1)+\ldots+E T_{c}(N)\right)
\end{array}\right]_{N \times 1}
\end{gathered}
$$

then the inequality constraints (11) can be written in the standard form of matrix $A$ and vector $b$ as,

$$
A=\left[\begin{array}{c}
A_{1} \\
-A_{1}
\end{array}\right]_{2 N \times N} \quad b=\left[\begin{array}{c}
b_{1} \\
b_{2}
\end{array}\right]_{2 N \times 1}
$$


Similarly the linear equality constraint 12 where irrigation is banned is between $11^{\text {th }}$ hour and $15^{\text {th }}$ hour can be represented by

$$
A_{e q}=\left[\begin{array}{ccc:ccccccc}
0 & \ldots & 0 & 0 & \ldots & 0 & 0 & \ldots & 0 \\
\vdots & \ddots & \vdots & \vdots & \ddots & \vdots & \vdots & \ddots & \vdots \\
0 & \ldots & 0 & 0 & \ldots & 0 & 0 & \ldots & 0 \\
\hdashline 0 & \ldots & 0 & 1 & \ldots & 0 & 0 & \ldots & 0 \\
\vdots & \ddots & \vdots & \vdots & \ddots & \vdots & \vdots & \ddots & \vdots \\
0 & \ldots & 0 & 0 & \ldots & 1 & 0 & \ldots & 0 \\
\hdashline 0 & \ldots & 0 & 0 & \ldots & 0 & 0 & \ldots & 0 \\
\vdots & \ddots & \vdots & \vdots & \ddots & \vdots & \vdots & \ddots & \vdots \\
0 & \ldots & 0 & 0 & \ldots & 0 & 0 & \ldots & 0
\end{array}\right]_{N \times N} \quad b_{e q}=\left[\begin{array}{c}
0 \\
\vdots \\
0
\end{array}\right]_{N \times 1}
$$

and the boundary conditions are represented by low and upper bounds:

$$
L_{B}=\left[\begin{array}{lll}
0 & \ldots & 0
\end{array}\right]_{N \times 1}^{T} \quad U_{B}=\left[\begin{array}{lll}
1 & \ldots & 1
\end{array}\right]_{N \times 1}^{T}
$$

This optimization problem is solved using the COIN Branch and Cut (Cbc) solver ${ }^{4}$, in the Matlab interface OPTI toolbox ${ }^{5}$ preferred for its high solving speed.

\subsection{Model for optimal scheduling with rooftop water harvesting}

Unlike the previous case, this model incorporates RWH involving an energy model of the pump subjected to the TOU tariff. The controller optimally schedules the on/off status of the utility valve and the pump based on the water restriction periods and the TOU tariff in order to minimize the cost of potable water and energy used. Hence, the water cost is conserved through using less water as well as shifting the irrigation to the low solar illumination periods. Likewise, cost of energy is reduced through using less energy to pump the water as well as load shifting by the TOU tariff.

This model assumes that the utility water is not reliable to irrigate directly hence the need to store it too, as is the case in many developing nations.

\subsubsection{Objective function}

Here, the objective is to minimize the cost of water and energy consumed during the irrigation. The objective function, $J$, is therefore,

$$
J=\alpha_{1} \sum_{j=1}^{N} p_{w} Q_{1} u_{1}(j)+\alpha_{2} \sum_{j=1}^{N} p_{m} p_{e}(j) u_{2}(j)
$$

where $\alpha_{1}$ and $\alpha_{2}$ are dimensionless weight factors, $p_{m}$ is the pump's rating and $p_{e}(j)$ is the price of electricity in a sampling interval. The weighting factors are chosen such that $\sum \alpha=1$ and all the weights are positive leading to a convex combination of the objectives. The values assigned to these weights are chosen relative to the importance of each objective function [39].

\footnotetext{
${ }^{4}$ Cbc https : //projects. coin-or.org/Cbc

${ }^{5}$ OPTI Toolbox http://www.i2c2.aut.ac.nz/Wiki/OPTI/
} 


\subsubsection{Constraints}

\section{A Soil water balance}

The soil water content in constraint (11) now becomes

$$
d_{l} \leq S(0)+\sum_{i=1}^{j}\left(\frac{Q_{2}}{A_{\text {lawn }}} u_{2}(i)+P(i)-E T_{c}(i)\right) \leq d_{u}, \quad(1 \leq j \leq N)
$$

\section{B Tank's capacity}

The volume of the water stored in the tank in the $j^{\text {th }}$ sampling interval is,

$$
V(j)=V(j-1)+Q_{1} u_{1}(j)-Q_{2} u_{2}(j)+A_{r t} P(j)
$$

The quantity $A_{r t} P(j)$ is the volume of the harvested rain water in the tank with $A_{r t}$ being the area of the rooftop. Expressing this volume in terms of the initial volume $V(0)$ in the tank using recurrence manipulation gives,

$$
V(j)=V(0)+\sum_{i=1}^{j}\left(Q_{1} u_{1}(i)-Q_{2} u_{2}(i)+A_{r t} P(i)\right) \quad(1 \leq j \leq N)
$$

This volume is restricted by the tank's dimensions as follows

$$
V_{l} \leq V(0)+\sum_{i=1}^{j}\left(Q_{1} u_{1}(i)-Q_{2} u_{2}(i)+A_{r t} P(i)\right) \leq V_{u}
$$

where $V_{l}$ and $V_{u}$ are the minimum and maximum volumes of the water in the tank respectively.

\section{Pump maintenance cost}

Although the pump maintenance cost cannot be easily quantified, the total number of its switching is used to estimate the cost. Frequent switching (on/off) increases the mechanical stress induced in the pump [40] causing more wear and tear thereby increasing the maintenance cost while reducing the pump's life [41]. It is therefore necessary to minimize the interruption of the pump while in operation [42] by allowing a wider operation band [43].

In this paper, we propose two methods to deal with the issue. We called the first method the constraint method, which restricts the pump to a maximum number of switching on, $s_{\max }$, during the control horizon.

$$
\sum_{j=1}^{N-1}\left(u_{2}(j+1)-u_{2}(j)\right)^{2} \leq 2 s_{\max }
$$

In this equation, the status of the pump at two adjacent sampling intervals is compared throughout the control horizon. The sum of the squares of this comparison is set to a maximum switching of $2 s_{\max }$ in order to effectively minimize the maintenance cost.

The second method is described in section 2.4 


\section{$D$ Watering restriction}

The watering restriction constraint (12) now becomes.

$$
u_{2}(i)=0 \quad \forall i \in\left[\frac{11}{t_{s}}, \frac{15}{t_{s}}\right]
$$

\section{E Boundaries}

In addition to bounds $(13)$, the pump switch is bounded as

$$
0 \leq u_{2}(j) \leq 1 \quad(1 \leq j \leq N)
$$

\subsubsection{Algorithm}

The generalized optimization formulation is similar to section 2.2 .3 with the exception of the non-linear inequality constraint notation $C(X) \leq d$. Vector $X$ contains the control variables which are the status of the solenoid valve, $u_{1}$, controlling the flow of the municipal water into the tank and the status of the switch controlling the pump, $u_{2}$. Therefore,

$$
X=\left[u_{1}(1), \ldots, u_{1}(N), u_{2}(1), \ldots, u_{2}(N)\right]_{2 N \times 1}^{T}
$$

From objective function (22),

$$
f^{T}=\left[\begin{array}{llllll}
\alpha_{1} Q_{1} & \ldots & \alpha_{1} Q_{1} p_{w} & \alpha_{2} p_{m} p_{e}(1) & \ldots & \alpha_{2} p_{m} p_{e}(N)
\end{array}\right]_{1 \times 2 N}
$$

If we denote

$$
\begin{aligned}
& A_{1}^{\prime}=\left[\begin{array}{ll}
0 & A_{1}
\end{array}\right]_{N \times 2 N} \\
& A_{3}=\left[\begin{array}{cccccccc}
-\frac{Q_{1}}{A_{\text {tank }}} & 0 & \ldots & 0 & \frac{Q_{2}}{A_{\text {tank }}} & 0 & \ldots & 0 \\
-\frac{Q_{1}}{A_{\text {tank }}} & -\frac{Q_{1}}{A_{\text {tank }}} & \ldots & 0 & \frac{Q_{2}}{A_{\text {tank }}} & \frac{Q_{2}}{A_{\text {tank }}} & \ldots & 0 \\
\vdots & \vdots & \ddots & \vdots & \vdots & \vdots & \ddots & \vdots \\
-\frac{Q_{1}}{A_{\text {tank }}} & -\frac{Q_{1}}{A_{\text {tank }}} & \ldots & -\frac{Q_{1}}{A_{\text {tank }}} & \frac{Q_{2}}{A_{\text {tank }}} & \frac{Q_{2}}{A_{\text {tank }}} & \ldots & \frac{Q_{2}}{A_{\text {tank }}}
\end{array}\right]_{N \times 2 N} \\
& b_{3}=\left[\begin{array}{c}
h(0)-h_{l}+\frac{A_{r t}}{A_{\text {tank }}} P(1) \\
h(0)-h_{l}+\frac{A_{r t}}{A_{\text {tank }}}(P(1)+P(2)) \\
\vdots \\
h(0)-h_{l}+\frac{A_{r t}}{A_{\text {tank }}}(P(1)+P(2)+\ldots+P(N))
\end{array}\right]_{N \times 1} \\
& b_{4}=\left[\begin{array}{c}
h_{u}-h(0)-\frac{A_{r t}}{A_{\text {tank }}} P(1) \\
h_{u}-h(0)-\frac{A_{r t}}{A_{\text {tank }}}(P(1)+P(2)) \\
\vdots \\
h_{u}-h(0)-\frac{A_{r t}}{A_{\text {tank }}}(P(1)+P(2)+\ldots+P(N))
\end{array}\right]_{N \times 1}
\end{aligned}
$$

where $h_{l}=\frac{V_{l}}{A_{\text {tank }}}$ and $h_{u}=\frac{V_{u}}{A_{\text {tank }}}$ are the lower and upper water height of the tank, respectively and $A_{\text {tank }}$ is the cross-sectional area of the tank. The quantity $h(0)=\frac{V(0)}{A_{\text {tank }}}$ is the initial height of the 
water in the tank. Then, the inequality constraints (23) and (26) can be written can be written in the standard form using matrix $A$ and vector $b$ as:

$$
A=\left[\begin{array}{c}
A_{1}^{\prime} \\
-A_{1}^{\prime} \\
A_{3} \\
-A_{3}
\end{array}\right]_{4 N \times 2 N} \quad b=\left[\begin{array}{l}
b_{1} \\
b_{2} \\
b_{3} \\
b_{4}
\end{array}\right]_{4 N \times 1}
$$

Similarly, the linear equality constraint 28, is written similarly to 20) with the following modifications

$$
A_{e q}^{\prime}=\left[\begin{array}{ll}
0 & A_{e q}
\end{array}\right]_{N \times 2 N} \quad b_{e q}^{\prime}=\left[b_{e q}\right]_{N \times 1}
$$

and the boundaries (13) and (29) become

$$
L_{B}^{\prime}=\left[\begin{array}{ll}
0 & L_{B}
\end{array}\right]_{2 N \times 1}^{T} \quad U_{B}^{\prime}=\left[\begin{array}{ll}
0 & U_{B}
\end{array}\right]_{2 N \times 1}^{T}
$$

Finally, the non-linear inequality constraint $(27)$ is written in the standard form $C(X) \leq d$ to become,

$$
(X(N+2)-X(N+1))^{2}+\ldots+(X(2 N)-X(2 N-1))^{2} \leq 2 s_{\max }
$$

This non-linear binary problem is solved using the $\operatorname{SCIP}^{6}$ optimization solver which is one of the fastest non-commercial solvers for mixed integer linear and non-linear programming available in the Matlab interface OPTI toolbox.

\subsection{The Pretoria method to reduce pump maintenance cost}

The maintenance cost of a pump, as mentioned earlier, is reduced by minimizing the switching times of the pump. The Pretoria method developed by Mathaba et.al. [42] introduces an auxiliary variable $s(j)$ represented by a value 1 whenever a start-up occurs. This changes the objective function (22) to,

$$
J=\alpha_{1} \sum_{j=1}^{N} p_{w} Q_{1} u_{1}(j)+\alpha_{2} \sum_{j=1}^{N} p_{m} p_{e}(j) u_{2}(j)+\alpha_{3} \sum_{j=1}^{N} s(j)
$$

where $\alpha_{3}$ is a weight factor. The objective is subject to constraints in 2.3.2 and

$$
\begin{aligned}
u_{2}(1)-s(1) & \leq 0 \\
u_{2}(j)-u_{2}(j-1)-s(j) & \leq 0
\end{aligned}
$$

with $s(j) \in\{0,1\}$. The first inequality in (41) initialises the auxiliary variable as the initial status of $u_{2}$ while the second favours the control that involves less switching.

In similar veins, the optimization can be re-written in the standard linear form as

$$
X=\left[\begin{array}{llllllll}
u_{1}(1) & \ldots & u_{1}(N) & u_{2}(1) & \ldots & u_{2}(N) & s(1) & \ldots s(N)
\end{array}\right]_{3 N \times 1}^{T}
$$

\footnotetext{
${ }^{6}$ SCIP http://scip.zib.de/
} 
and

$$
f^{T}=\left[\begin{array}{lllllllll}
\alpha_{1} Q_{1} & \ldots & \alpha_{1} Q_{1} p_{w} & \alpha_{2} p_{m} p_{e}(1) & \ldots & \alpha_{2} p_{m} p_{e}(N) & 1 & \ldots & 1
\end{array}\right]_{1 \times 3 N}
$$

If we denote

$$
A_{1}^{\prime \prime}=\left[\begin{array}{ll}
A_{1}^{\prime} & 0
\end{array}\right]_{N \times 3 N} \quad A_{3}^{\prime}=\left[\begin{array}{ll}
A_{3} & 0
\end{array}\right]_{N \times 3 N}
$$

and

$$
\begin{aligned}
A_{5} & =\left[\begin{array}{ccccccccccccc}
0 & \ldots & 0 & 1 & 0 & 0 & \ldots & 0 & -1 & 0 & 0 & \ldots & 0 \\
0 & \ldots & 0 & -1 & 1 & 0 & \ldots & 0 & 0 & -1 & 0 & \ldots & 0 \\
0 & \ldots & 0 & 0 & -1 & 1 & \ldots & 0 & 0 & 0 & -1 & \ldots & 0 \\
\vdots & \ddots & \vdots & \vdots & \vdots & \ddots & \ddots & \vdots & \vdots & \vdots & \vdots & \ddots & \vdots \\
0 & \ldots & 0 & 0 & 0 & \ldots & -1 & 1 & 0 & 0 & 0 & \ldots & -1
\end{array}\right]_{N \times 3 N} \\
b_{5} & =\left[\begin{array}{llllllll}
0 & 0 & 0 & \ldots & 0
\end{array}\right]_{N \times 1}^{T}
\end{aligned}
$$

then the linear inequality constraints (23), (26) and (41) become,

$$
A=\left[\begin{array}{c}
A_{1}^{\prime \prime} \\
-A_{1}^{\prime \prime} \\
A_{3}^{\prime} \\
-A_{3}^{\prime} \\
A_{5}^{\prime}
\end{array}\right]_{5 N \times 3 N} \quad b=\left[\begin{array}{l}
b_{1} \\
b_{2} \\
b_{3} \\
b_{4} \\
b_{5}
\end{array}\right]_{5 N \times 1}
$$

while the linear equality constraint $(28)$ becomes,

$$
A_{e q}^{\prime \prime}=\left[\begin{array}{ll}
A_{e q}^{\prime} & 0
\end{array}\right]_{N \times 3 N} \quad b_{e q}^{\prime \prime}=\left[b_{e q}^{\prime}\right]_{N \times 1}
$$

and finally, boundaries (13) and (29) become,

$$
L_{B}^{\prime \prime}=\left[\begin{array}{ll}
L_{B}^{\prime} & 0
\end{array}\right]_{3 N \times 1}^{T} \quad U_{B}^{\prime \prime}=\left[\begin{array}{ll}
U_{B}^{\prime} & 0
\end{array}\right]_{3 N \times 1}^{T}
$$

This binary linear problem is solved using the SCIP solver.

\section{General data}

\subsection{Case study}

Since there is no consolidated information on domestic water consumption in South Africa [21], the case used was the Acclima TDT scheduling done by Blonquist Jr. et.al. [29], who used the Kentucky bluegrass on a $280 \mathrm{~m}^{2}$ field plot with Millville Silt Loam soil. The estimated rooting depth of the turfgrass was $30 \mathrm{~cm}$ with a MAD of 0.5 . Further, the average daily evapotranspiration, $E T_{c}$, was $3.77 \mathrm{~mm}$ and a precipitation of $1 \mathrm{~mm}$ was experienced. A controller was connected to the solenoid valve on the pipe to irrigate the lawn using a gear-driven sprinkler head (Hunter ${ }^{\circledR}$ PGP with a \#9 in. nozzle) with an approximate flow rate of $0.374 \mathrm{l} / \mathrm{s}$

\footnotetext{
${ }^{7}$ Hunters product catalogue www . hunterindustries . com
} 
Since the above case used municipal water directly without storing, a case study was conducted in Pretoria which showed that a typical house has a rooftop area of $120 \mathrm{~m}^{2}$ and lawn irrigation is normally done in the morning between 8 and 10 am when workers report on duty.

Further, in this paper, the initial value of the soil water content, $S(0)$, and water level in the tank, $h(0)$, are taken as $29.1 \mathrm{~cm}$ and $18 \mathrm{~cm}$ respectively. In the model with RWH, equal weighting factors $\left(\alpha_{1}=\alpha_{2}=0.5\right)$ are chosen, because most end-users prefer both energy and water savings. Similarly, in the Pretoria method, $\alpha_{1}=\alpha_{2}=0.4$, and the pump maintenance cost weighting factor, $\alpha_{3}=0.2$ has less weight. Finally, in the constraint method, the maximum allowable number of pump switching, $s_{\max }=3$.

\subsection{Time-of-use electricity tariff}

The time-of-use (TOU) tariff is commonly used globally [44] and it can vary by time of day, day of week and season [45]. Eskom's TOU Homeflex structure ${ }^{8}$ for residential consumers given below is used [46].

$$
p_{e}(t)=\left\{\begin{array}{lll}
p_{\text {off }}=0.6281 & R / K w h & \text { if } t \in[0,6] \cup[10,18] \cup[20,24] \\
p_{\text {peak }}=1.9935 & R / K w h & \text { if } t \in[7,10] \cup[18,20]
\end{array}\right.
$$

where $p_{\text {off }}$ is the off peak price, $p_{\text {peak }}$ is the peak time price, $R$ is the South African currency, Rand, and $t$ is the time of day in hours. The tariff has five charge components as service charge, net-work charge, environmental levy, peak charge and off-peak charges [47]

\subsection{Water tariffs}

The city of Tshwane ${ }^{9}$ has various water tariffs for different classes of consumers and the domestic consumers are charged using the rates in table 1. The monthly amount of water used for

Table 1: City of Tshwane water tariff for 2014/2015

\begin{tabular}{|l|c|c|c|c|c|c|c|c|}
\hline Volume $\left(\mathrm{m}^{3} /\right.$ month $)$ & $0-6$ & $7-12$ & $13-18$ & $19-24$ & $25-30$ & $31-42$ & $43-72$ & $>72$ \\
\hline Rates $\left(R / m^{3}\right)$ & 6.81 & 9.72 & 12.77 & 14.77 & 16.89 & 18.25 & 19.53 & 20.91 \\
\hline
\end{tabular}

irrigation is assumed to be less than $6 \mathrm{~m}^{3}$ meaning the unit price of water used $p_{w}=6.81\left(\mathrm{R} / \mathrm{m}^{3}\right)$.

\subsection{Water tank and pump}

There are various companies supplying water tanks in South Africa. Jojo's $1000 l$ cylindrical water tank with a diameter and height of 1.1 and $1 \mathrm{~m}$ respectively is used chosen. The lower and upper levels of the water in the tank are set as 0.12 and $1 \mathrm{~m}$, respectively to avoid spilling the water from the tank as well as running it completely empty.

The pump chosen for this model is the Al-Ko HW 3000 Classid $^{11}$, with a power rating of 650 $W$ and a flow rate of $3.1 \mathrm{~m}^{3} / \mathrm{h}$. It is ideal for small sprinklers and domestic applications.

\footnotetext{
${ }^{8}$ Eskom tariffs and charges booklet 2011/2012. Www. eskom . co.za

${ }^{9}$ Tshwane Municipal Tariffs 2014/2015 www.tshwane.gov.za

${ }^{10}$ Water tank www.jojo.co.za

${ }^{11}$ www.urbanrainsystems.co.za/accessories/accessories.asp
} 


\section{Simulation results and discussion}

\subsection{Optimal scheduling without rooftop water harvesting}

Figure 3 a shows the optimal irrigation schedule. The schedule has three switching regimes with two taking place early in the morning. Another schedule takes place in the evening taking advantage of the low evapotranspiration rates as well as obey the by-laws. The water content in the soil, shown in figure 3b, is maintained within the required range, ensuring that there is no drainage

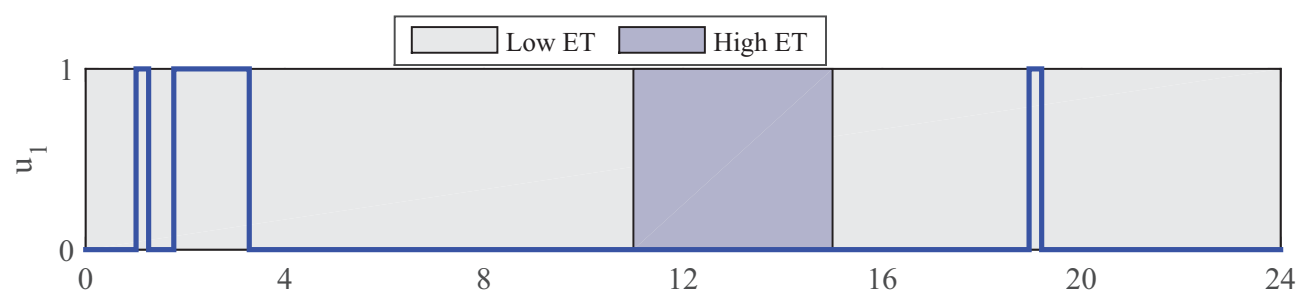

(a) Optimal schedule

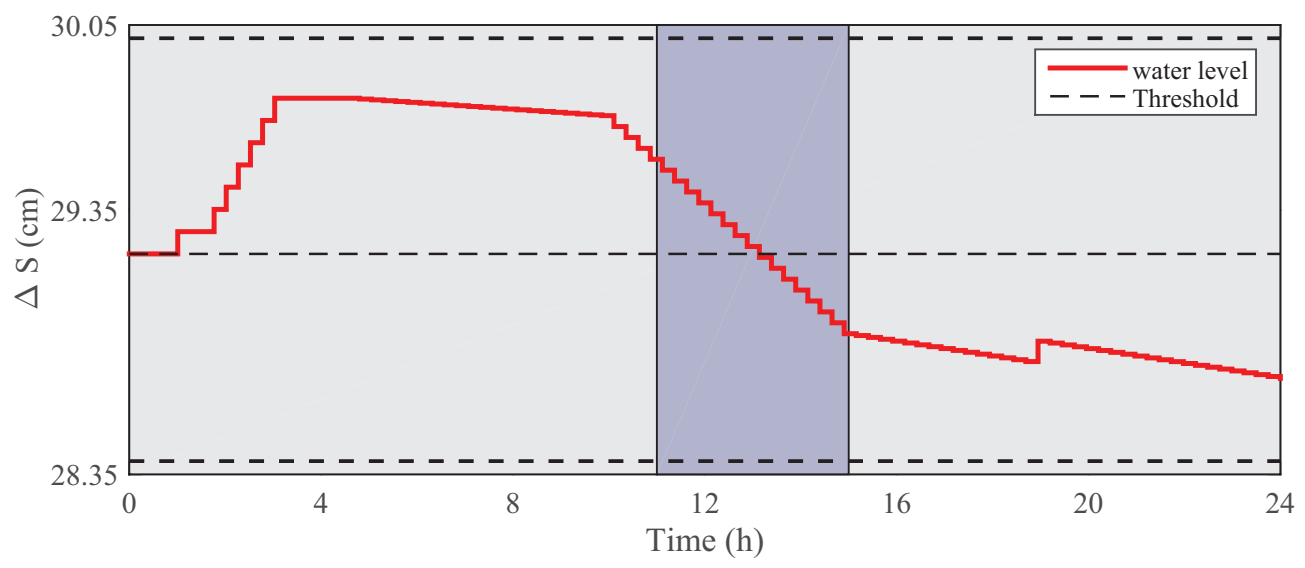

(b) Soil water variation

Figure 3: Optimal schedule and variation of the state variable.

from the soil as well as the soil doesn't become too dry.

\subsection{Comparison of the switching strategies}

Figure 4 shows the comparison of the two switching minimization strategies used to reduce the pump switching frequency. The legend used is the same throughout this paper. The Pretoria method (figure $4 \mathrm{a}$ ) optimally reduces the switching to the minimum feasible times. In this case, the strategy reduces the switching to two times during the entire control horizon. On the contrary, the constraint method (figure 4b), which explicitly sets the maximum number of possible switching $\left(s_{\max }=3\right)$, actually switches the pump 3 times during the control horizon. The constraint method however runs at a risk of infeasibility if the irrigation demand increases to a level where the pump must switch on more than the set $s_{\max }$. This shows that the Pretoria method is more effective in reducing the maintenance cost than the constraint method and it is therefore used in the later sections. It is important to note that both strategies incur the same cost of energy during the 


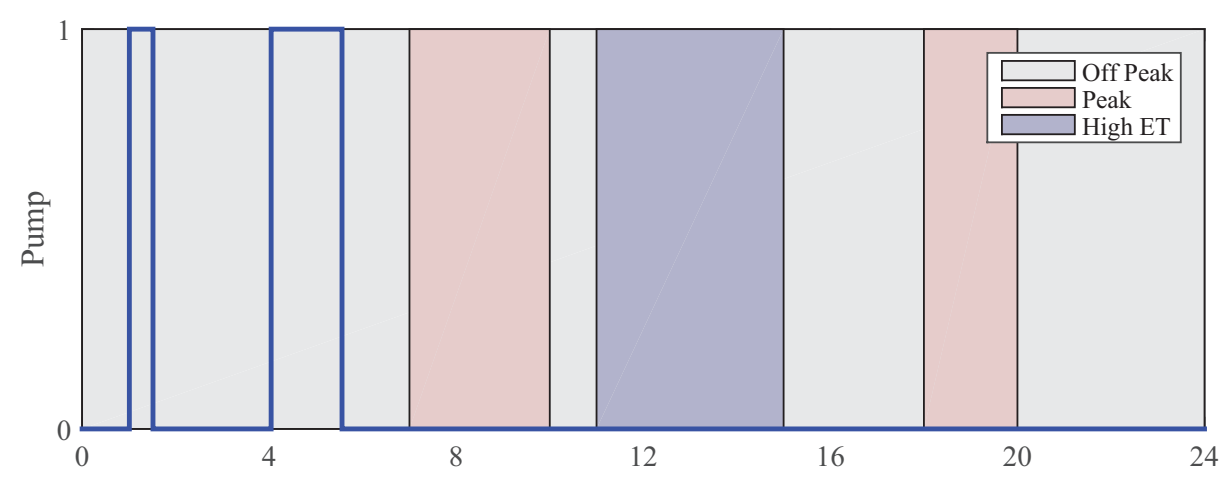

(a) Pretoria method

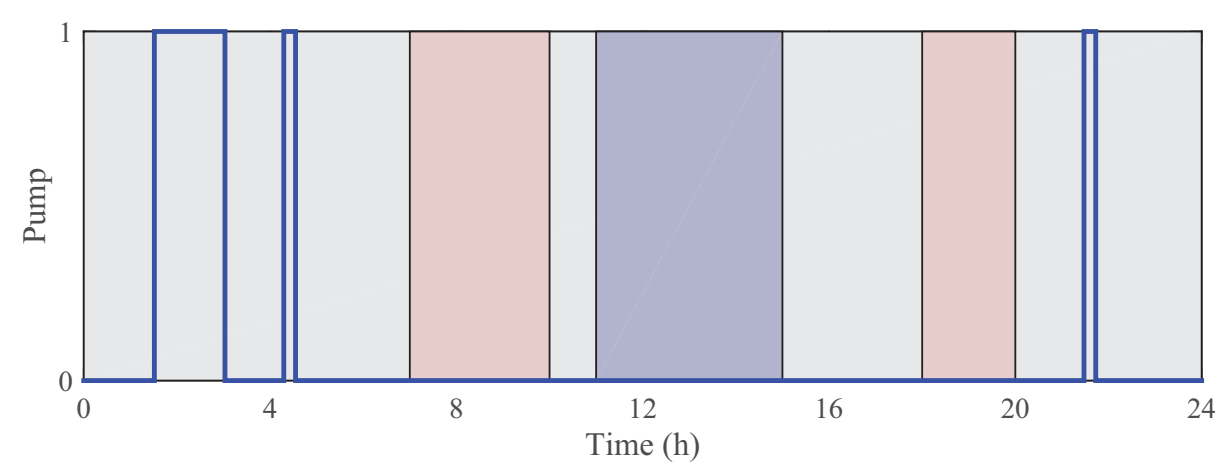

(b) Constraint method

Figure 4: Comparison of the switching minimization strategies.

period, as the same amount of water is pumped for irrigation. Further, although in one day, the extra switching regime in the constraint method may not have very high difference in maintenance cost, over a long period of time, the extra switching will affect the maintenance cost by lowering the life cycle of the pump.

\subsection{Optimal scheduling with rooftop water harvesting}

Two scenarios are analysed when incorporating rooftop water harvesting. The optimal schedules of the valve and the pump are shown in figure 5 in cases where there is no precipitation and when 1-mm of precipitation event occurs. The valve controlling the municipal water into the tank (figures 5a and 5c) uses negligible amount of power, hence it is allowed to operate throughout the control horizon irrespective of whether it is peak or off-peak in the TOU tariff.

This model has two state variables; height of water in the tank and depth of water in the soil. The height of water in the tank, $h(j)=\frac{v(j)}{A_{\text {tank }}}$, is obtained using equation 25] while the soil water variation is obtained using equation (10). The variation of these variables during the control horizon is shown in figures 6 and 7 respectively. In both figures, left vertical axis represents the water level either in the tank or soil while the rainfall event is shown by the right axis. 


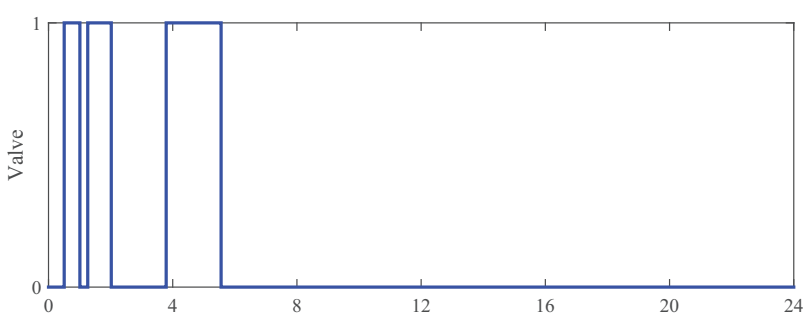

(a)

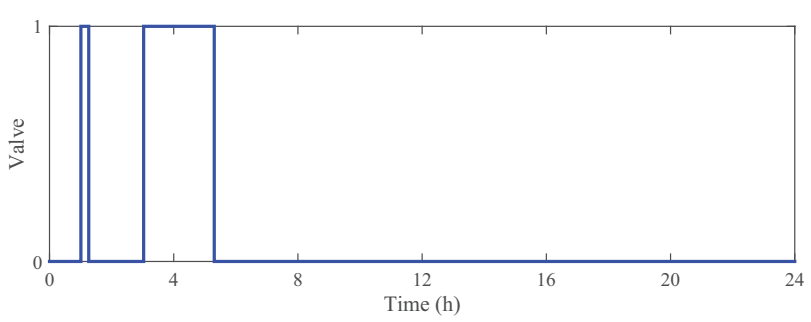

(c)

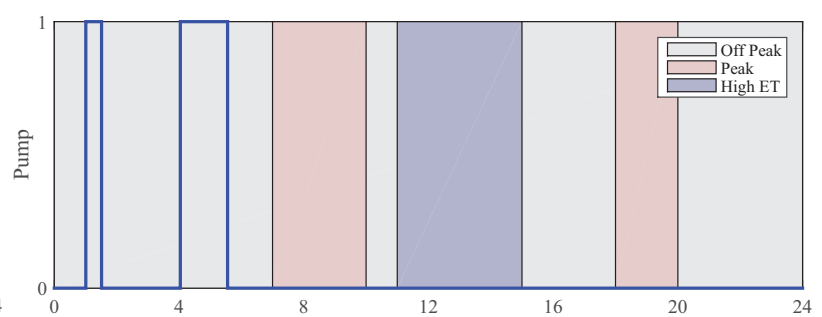

(b)

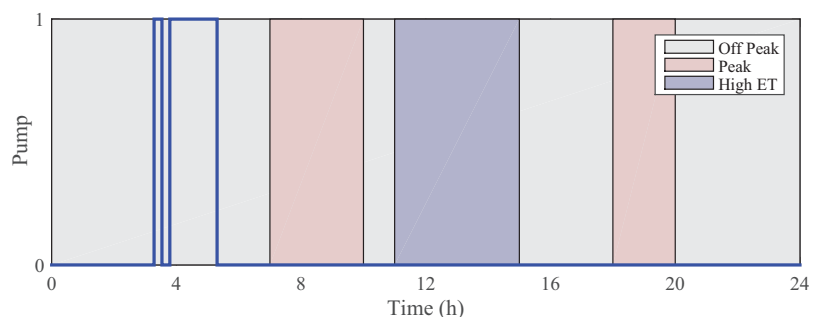

(d)

Figure 5: Optimal schedules of the valve and tank; (a,b) with no precipitation (c,d) with $1 \mathrm{~mm}$ rainfall recorded.

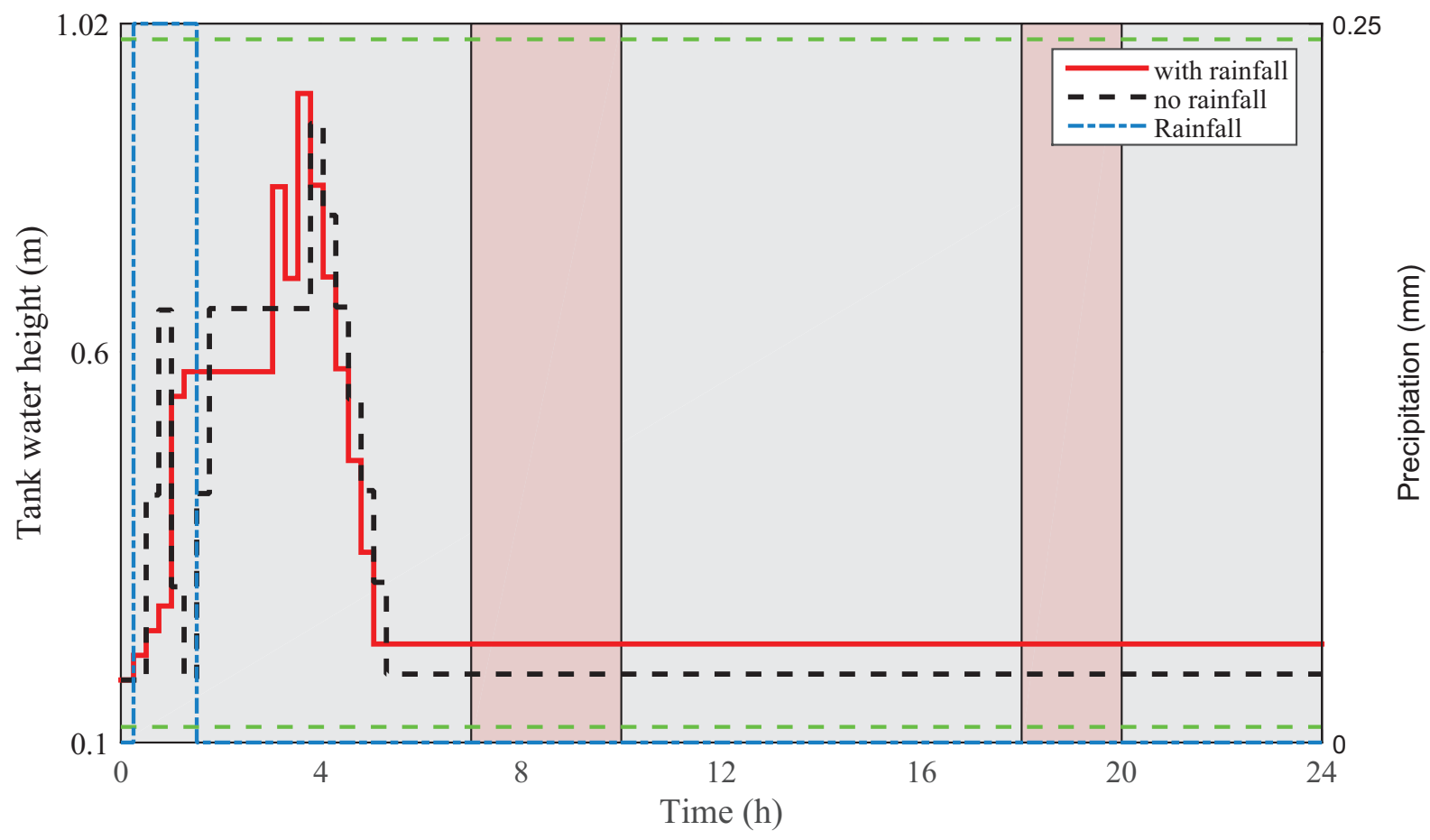

Figure 6: Variation of the water in the tank with and without precipitation.

\subsubsection{Scenario 1: Optimal schedule with no precipitation}

With no precipitation, or zero rainfall recorded, the tank is purely filled with utility water with the valve optimally operating as shown in figure 5a. This results from the demand of water in the 


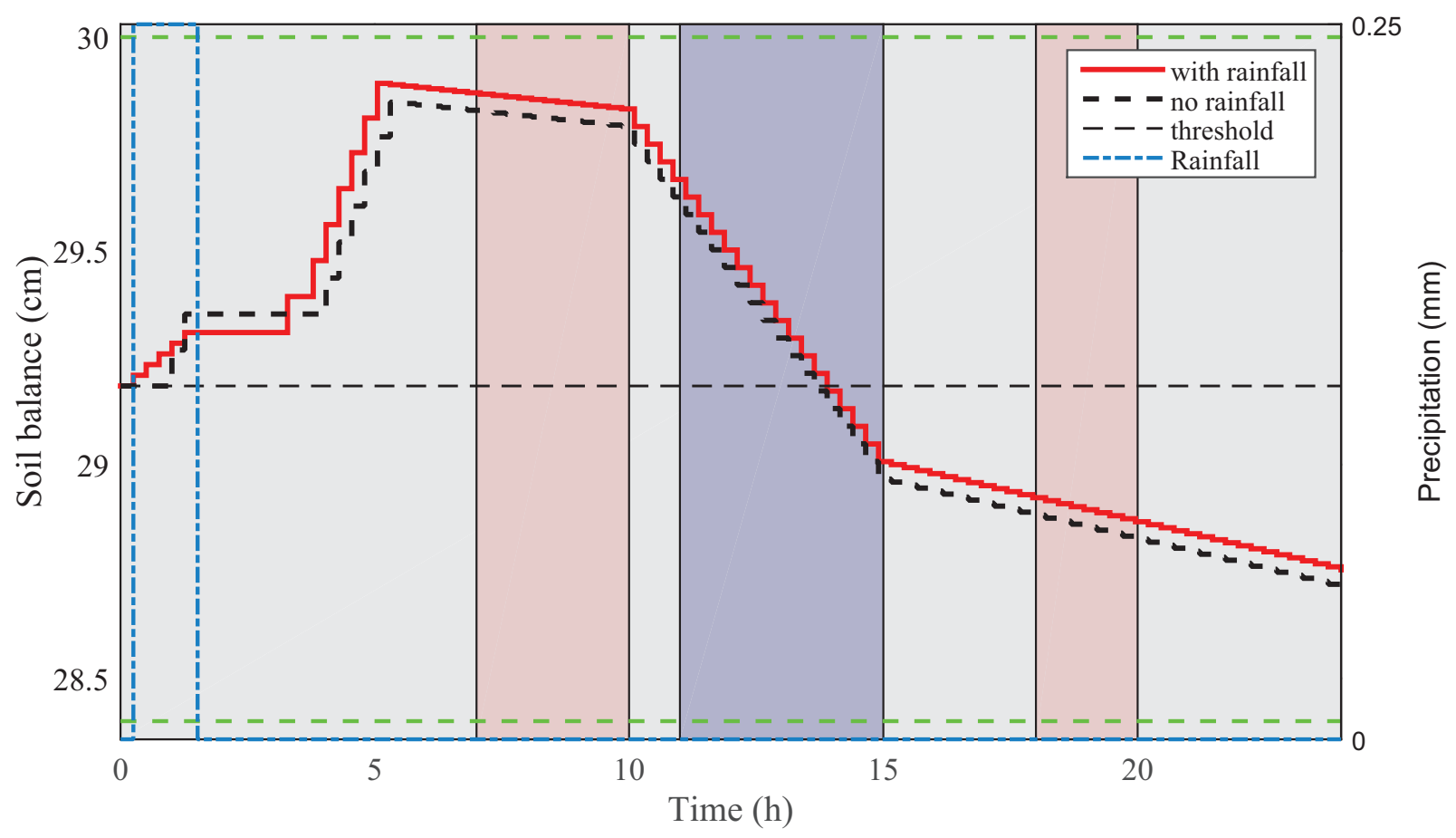

Figure 7: Soil water balance with and without precipitation.

lawn which is met by optimally operating the pump as shown in figure $5 b$. The optimal schedule (figures $5 \mathrm{a}$ and 5b) have three tank filling and two irrigation regimes to ensure that the water level in the tank and the soil remain within the required height and depth respectively. The solenoid valve switches on at 00:30 causing the water level in the tank to rise to $0.65 \mathrm{~m}$. The pump then switches on between 01:00 to 01:30 leading to the water height in the tank dropping to $0.18 \mathrm{~m}$ while the water level in the soil rises to $29.35 \mathrm{~cm}$. The water height in the tank then rises again to $0.66 \mathrm{~m}$ until the solenoid valve switches off at 02:15 hours. The water level then remains constant both in the tank and the soil since both solenoid valve and pump are off and since it is early morning, the evapotranspiration losses are assumed as negligible. The controller then predicts that another irrigation is scheduled to start at 04:00 and opens the solenoid valve at 03:45. For the 15 minutes that only the solenoid valve is open, the water height in the tank further rises to $0.89 \mathrm{~m}$ and thereafter starts dropping when irrigation starts until when the pump switches off at 05:30 hours, where it remains constant for the rest of the day. This last irrigation event also causes the water level in the soil to rise to $29.85 \mathrm{~cm}$, and thereafter the water content drops due to the evapotranspiration over the control horizon.

Even though this scenario has no rain harvested, the irrigation schedule differs with the schedule in section 4.1 because of addition of the pump and water storage tank. However, about $6.7 \mathrm{~mm}$ of water is used for irrigation in both cases. 


\subsubsection{Scenario 2: Optimal schedule with precipitation}

The optimal schedules for the valve and pump obtained assuming about 1-mm of precipitation event between midnight and $1 \mathrm{AM}$ are shown in figures $5 \mathrm{c}$ and $5 \mathrm{~d}$. Since the rain is assumed to fall both on the rooftop and the lawn, both the valve and pump optimal schedules switch for less duration than when there is no precipitation taking place. The solenoid valve switches on at 01:00 hours but since there is precipitation taking place, it switches off in the next sampling interval. The harvesting of rain water and opening of the valve cause the height of the water in the tank to rise to $0.57 \mathrm{~m}$. This precipitation event also causes the water level in the soil to rise to $29.31 \mathrm{~cm}$. Thereafter the water level remains constant in both the tank and soil until 03:00 for the tank when the solenoid next switches on and 03:15 when the pump switches on. The pump switches off at 03:30 for 15 minutes enabling the water height in the tank to reach a peak of $0.93 \mathrm{~m}$. Thereafter the pump switches on, while the solenoid valve is still filling the tank, until 05.15, where they both switch off. During this duration, the water height in the tank drops to $0.23 \mathrm{~m}$ while the water level in the soil rises to $29.89 \mathrm{~cm}$. Thereafter, both the solenoid valve and the pump remain off for the rest of the control horizon. Therefore, the water height in the tank remain constant at $0.23 \mathrm{~m}$ while the water level in the soil drops due to evapotranspiration losses to $28.73 \mathrm{~cm}$. About $5.9 \mathrm{~mm}$ of water is pumped for irrigation in this scenario.

With the 1-mm precipitation event, about $120 \mathrm{l}$ of rain water is harvested from the rooftop and stored in the tank. Even though the same 1-mm rain is assumed to have fallen on the lawn, it is not sufficient to maintain the soil water content as required during the control horizon leading to about $5.9 \mathrm{~mm}$ of irrigation water being applied, which is less than $6.7 \mathrm{~mm}$ applied when no precipitation takes place. This leads to about $0.4 \mathrm{~mm}$ more water content being left in the soil at the end of the control horizon as seen in figure 7. Part of this $5.9 \mathrm{~mm}$ of irrigation water is met by harvested water stored in the tank effectively leading to conservation of $120 \mathrm{l}$ of municipal water during this day. Over a long time, with more precipitation events, more water would be harvested leading to even higher water conservation.

\subsection{Discussion}

The optimal irrigation scheduling without RWH is applicable if the water is always reliable and no rain water can be harvested from the building. In cases where the utility water is not reliable, like in developing nations, the water needs to be stored and pumped. The model incorporating RWH becomes useful.

Table 2 shows the comparison of the two optimal irrigation scheduling and the techniques used by Blonquist Jr. et.al. [29]. The Acclima TDT sensor was connected to the the Acclima CS3500 controller and the irrigation results compared with the regular irrigation practice in the area [29]. The amount of irrigation water used in both models with and without RWH is the same. When the rain falls on the lawn, less water will be required to irrigate in order to meet the required level making the amount used in this scenario same in both models. Given the optimal model with no RWH is directly coupled to the municipal water, there are no associated direct energy costs. However, the model results in $14.7 \%$ of water conserved in relation to the Acclima TDT model, leading to a similar cost saving in a day. The water conservation is even higher; $17.4 \%$ with a similar cost saving, in relation to the regular water application. Unlike the other methods, the model reduces the amount irrigated even when a small amount of rainfall is experienced. 
Table 2: Comparison of irrigation and energy amounts and the associated cost

\begin{tabular}{|c|c|c|c|c|c|}
\hline \multirow{2}{*}{ Mode } & \multicolumn{2}{|c|}{ Irrigation water } & \multicolumn{2}{|c|}{ Pumping Energy } & \multirow{2}{*}{$\begin{array}{l}\text { Total } \\
\text { Cost } \\
(R / d a y)\end{array}$} \\
\hline & $\begin{array}{l}\text { Amount } \\
(\mathrm{mm} / \text { day })\end{array}$ & $\begin{array}{l}\text { Cost } \\
(R / \text { day })\end{array}$ & $\begin{array}{c}\text { Amount } \\
(K w h / d a y)\end{array}$ & $\begin{array}{c}\text { Cost } \\
(R / d a y)\end{array}$ & \\
\hline \multicolumn{6}{|l|}{ Optimal(No } \\
\hline \multicolumn{6}{|l|}{$\mathrm{RWH}$} \\
\hline $\mathrm{P}=0 \mathrm{~mm}$ & 6.73 & 12.90 & - & - & 12.90 \\
\hline $\mathrm{P}=1 \mathrm{~mm}$ & 5.90 & 11.30 & - & - & 11.30 \\
\hline Acclima TDT & 6.92 & 13.20 & - & - & 13.20 \\
\hline Regular & 7.14 & 13.70 & - & - & 13.70 \\
\hline \multicolumn{6}{|l|}{ Optimal(RWH) } \\
\hline $\mathrm{P}=0 \mathrm{~mm}$ & 6.73 & 12.90 & 1.3000 & 0.82 & 13.72 \\
\hline $\mathrm{P}=1 \mathrm{~mm}$ & 5.90 & $10.50^{\mathrm{a}}$ & 1.1375 & 0.72 & 11.22 \\
\hline Acclima TDT & 6.92 & 13.20 & $1.337^{\mathrm{b}}$ & 0.84 & 14.04 \\
\hline Regular & 7.14 & 13.70 & $1.379^{\mathrm{b}}$ & $2.75^{\mathrm{c}}$ & 16.45 \\
\hline \multicolumn{6}{|c|}{$\begin{array}{l}\text { a This cost was obtained after reduction of } 120 l \text { harvested water from the total water } \\
\text { irrigated. } \\
\text { b Pumping assumed to be done with the energy proportional to the amount of water irri- } \\
\text { gated. } \\
\text { c Irrigation normally carried out in the morning during peak time. }\end{array}$} \\
\hline
\end{tabular}

The optimal model with RWH introduces energy costs from the pumping. Assuming there is no harvested water in the tank, the operational cost of the model with RWH is about $13 \%$ higher than the model with no RWH. However, with $1 \mathrm{~mm}$ precipitation, the model with RWH exhibits the lowest operational cost. It leads to about $7.1 \%$ reduction on the cost of water used for irrigation with respect to the optimal schedule with no RWH with the precipitation. There is a further $20.5 \%$ and $23.4 \%$ savings in the cost of water relative to the Acclima TDT and the regular water application respectively. In addition, the model results in $14.3 \%$ and $73.8 \%$ savings in energy cost relative to the Acclima TDT scheduling and regular irrigation practice respectively. The high savings in energy cost when compared to the regular irrigation occur because regular irrigation normally takes place during peak time.

It is important to note that although RWH introduces energy costs, the optimal irrigation scheduling with RWH, greatly reduces the operational cost by saving both the water and energy.

\section{Conclusion}

Optimal irrigation scheduling in urban lawns can have direct and indirect benefits. This paper shows the potential direct benefits including significant savings in the cost water by about $14.7 \%$ and $17.4 \%$ relative to the Acclima TDT scheduling and regular irrigation, respectively, when optimally scheduling using municipal water directly. Optimal scheduling with RWH lowers this cost even further by $20.5 \%$ and $23.4 \%$ relative to the Acclima TDT scheduling and regular irrigation respectively. Following implementation of water conservation measures, the consequent potential 
savings in energy cost in the RWH model are $14.3 \%$ and $73.8 \%$ relative to the Acclima TDT and regular irrigation respectively. These savings result from the load shifting to off-peak times as well as just the necessary amount of water is pumped to the lawn. Furthermore, the Pretoria method maximizes the pump life by minimizing the maintenance cost resulting from switching frequency better.

The optimal models can potentially lead to improved economic efficiency through cost savings of both water and energy. In addition, the optimal model with RWH best suits application in developing nations where water demand far surpasses the supply requiring water storage. It not only leads to water conservation but also reduces the demand of potable water from municipal sources as well as shifting and reducing the load on the power utility.

\section{Acknowledgements}

The authors would like to thank the National Hub for Energy Efficiency and Demand Side Management (EEDSM) for supporting this research.

\section{References}

[1] M. Hafeez, J. Bundschuh, S. Mushtaq, Exploring synergies and tradeoffs: Energy, water, and economic implications of water reuse in rice-based irrigation systems, Applied Energy 114 (2014) 889 - 900.

[2] A. Plappally, J. Lienhard, Energy requirements for water production, treatment, enduse, reclamation, and disposal, Renewable and Sustainable Energy Reviews 16 (2012) 4818-4848.

[3] A. Fidar, F. Memon, D. Butler, Environmental implications of water efficient microcomponents in residential buildings, Science of the Total Environment 408 (2010) 5828-5835.

[4] S. Muthukumarana, K. Baskarana, N. Sextonb, Quantification of potable water savings by residential water conservation and reuse - a case study, Resources, Conservation and Recycling 55 (2011) 945-952.

[5] United Nations World Water Report 4, Managing water under uncertainty and risk, facts and figures (2011).

[6] UNESCO, WMO, IAEA, The state of the resource, in: World Water Development Report, Vol. 2, UNESCO Publishing and Berghahn Books, 2006, Ch. 4.

[7] M. Gulati, I. Jacobs, A. Jooste, D. Naidoo, S. Fakir, The water-energy-food security nexus: Challenges and opportunities for food security in south africa, Aquatic Procedia 1 (2013) 150 - 164.

[8] Z. Wu, X. Xia, B. Wang, Improving building energy efficiency by multiobjective neighborhood field optimization, Energy and Buildings 87 (2015) $45-56$.

[9] A. Dubreuil, E. Assoumou, S. Bouckaert, S. Selosse, N. Mazi, Water modeling in an energy optimization framework- the water-scarce middle east context, Applied Energy 101 (2013) 268 - 279.

[10] C. Cheng, Study of the inter-relationship between water use and energy conservation for a building, Energy and Buildings 34 (3) (2002) $261-266$.

[11] Y. Chiu, C. Liaw, L. Chen, Optimizing rainwater harvesting systems as an innovative approach to saving energy in hilly communities, Renewable Energy 34 (3) (2009) 492 - 498.

[12] S. J. Kenway, R. Scheidegger, T. A. Larsen, P. Lant, H.-P. Bader, Water-related energy in households: A model designed to understand the current state and simulate possible measures, Energy and Buildings 58 (0) (2013) $378-389$.

[13] U. E. Ekpenyong, J. Zhang, X. Xia, Mathematical modelling for the social impact to energy efficiency savings, Energy and Buildings 84 (2014) $344-351$.

[14] B. Wang, X. Xia, Optimal maintenance planning for building energy efficiency retrofitting from optimization and control system perspectives, Energy and Buildings 96 (2015) 299 - 308.

[15] S. M. Sichilalu, X. Xia, Optimal energy control of grid tied pv-diesel-battery hybrid system powering heat pump water heater, Solar Energy 115 (2015) 243-254. 
[16] Z. Wu, H. Tazvinga, X. Xia, Demand side management of photovoltaic-battery hybrid system, Applied Energy 148 (2015) $294-304$.

[17] W. Badenhorst, J. Zhang, X. Xia, Optimal hoist scheduling of a deep level mine twin rock winder system for demand side management, Electric Power Systems Research 81 (5) (2011) 1088 - 1095.

[18] A. Chatterjee, L. Zhang, X. Xia, Optimization of mine ventilation fan speeds according to ventilation on demand and time of use tariff, Applied Energy 146 (2015) 65 - 73.

[19] B. Gumbo, The status of water demand management in selected cities of southern africa, Physics and Chemistry of the Earth, Parts A/B/C 29 (15) (2004) 1225 - 1231.

[20] H. Lévite, H. Sally, J. Cour, Testing water demand management scenarios in a water-stressed basin in south africa: application of the WEAP model, Physics and Chemistry of the Earth, Parts A/B/C 28 (20) (2003) 779 786.

[21] Department of Water Affairs and Forestry, South Africa, Water conservation and demand management strategy for the water services sectors (August 2004).

[22] H. Jacobs, L. Geustyn, B. Loubser, Water-how is it used at home?, in: Proceedings of the Water Institute of South Africa Biennial Conference, 2006.

[23] J. L. du Plessis, Estimating domestic outdoor water demand for residential estates, Master's thesis, Stellenbosch University (April 2014).

[24] J. M. Kahinda, A. Taigbenu, R. Boroto, Domestic rainwater harvesting as an adaptation measure to climate change in south africa, Physics and Chemistry of the Earth, Parts A/B/C 35 (13) (2010) 742 - 751.

[25] J. M. Kahinda, A. Taigbenu, Rainwater harvesting in south africa: Challenges and opportunities, Physics and Chemistry of the Earth, Parts A/B/C 36 (14) (2011) 968 - 976.

[26] D. J. Sample, J. P. Heaney, Integrated management of irrigation and urban storm-water infiltration, Journal of water resources planning and management 132 (5) (2006) 362-373.

[27] S. Davis, M. D. Dukes, G. Miller, Landscape irrigation by evapotranspiration-based irrigation controllers under dry conditions in southwest florida, Agricultural Water Management 96 (12) (2009) 1828-1836.

[28] S. Davis, M. Dukes, Irrigation scheduling performance by evapotranspiration-based controllers, Agricultural Water Management 98 (1) (2010) 19 - 28.

[29] J. Blonquist Jr., S. Jones, D. Robinson, Precise irrigation scheduling for turfgrass using a subsurface electromagnetic soil moisture sensor, Agricultural Water Management 84 (1ф2) (2006) 153 - 165.

[30] A. Bocanegra-Martínez, J. M. Ponce-Ortega, F. Nápoles-Rivera, M. Serna-González, A. J. Castro-Montoya, M. M. El-Halwagi, Optimal design of rainwater collecting systems for domestic use into a residential development, Resources, Conservation and Recycling 84 (2014) 44 - 56.

[31] D. J. Sample, J. Liu, S. Wang, Evaluating the dual benefits of rainwater harvesting systems using reliability analysis, Journal of Hydrologic Engineering 18 (10) (2012) 1310-1321.

[32] D. J. Sample, J. Liu, Optimizing rainwater harvesting systems for the dual purposes of water supply and runoff capture, Journal of Cleaner Production 75 (2014) 174-194.

[33] S. Ward, D. Butler, F. A. Memon, Benchmarking energy consumption and $\mathrm{CO}_{2}$ emissions from rainwaterharvesting systems: an improved method by proxy, Water and Environment Journal 26 (2) (2012) 184-190.

[34] M. Talebpour, O. Sahin, R. Siems, R. Stewart, Water and energy nexus of residential rainwater tanks at an end uselevel: Case of australia, Energy and Buildings 80 (2014) 195-207.

[35] J. Reca, A. Garcia-Manzano, J. Martinez, Optimal pumping scheduling model considering reservoir evaporation, Agricultural Water Management 148 (0) (2015) 250 - 257.

[36] A. Dimoudi, M. Nikolopoulou, Vegetation in the urban environment: microclimatic analysis and benefits, Energy and buildings 35 (1) (2003) 69-76.

[37] M. McCready, M. Dukes, Landscape irrigation scheduling efficiency and adequacy by various control technologies, Agricultural Water Management 98 (4) (2011) 697 - 704.

[38] B. Numbi, J. Zhang, X. Xia, Optimal energy management for a jaw crushing process in deep mines, Energy 68 (2014) $337-348$.

[39] R. T. Marler, J. S. Arora, The weighted sum method for multi-objective optimization: new insights, Structural and multidisciplinary optimization 41 (6) (2010) 853-862.

[40] S. Zhang, X. Xia, Optimal control of operation efficiency of belt conveyor systems, Applied Energy 87 (6) 
(2010) $1929-1937$.

[41] A. M. Bagirov, A. Barton, H. Mala-Jetmarova, A. Al Nuaimat, S. Ahmed, N. Sultanova, J. Yearwood, An algorithm for minimization of pumping costs in water distribution systems using a novel approach to pump scheduling, Mathematical and Computer Modelling 57 (3) (2013) 873-886.

[42] T. Mathaba, X. Xia, J. Zhang, Analysing the economic benefit of electricity price forecast in industrial load scheduling, Electric Power Systems Research 116 (0) (2014) 158 - 165.

[43] A. J. van Staden, J. Zhang, X. Xia, A model predictive control strategy for load shifting in a water pumping scheme with maximum demand charges, Applied Energy 88 (12) (2011) 4785 - 4794.

[44] L. Zhang, X. Xia, J. Zhang, Improving energy efficiency of cyclone circuits in coal beneficiation plants by pump-storage systems, Applied Energy 119 (0) (2014) 306 - 313.

[45] X. Zhuan, X. Xia, Optimal operation scheduling of a pumping station with multiple pumps, Applied Energy 104 (0) (2013) $250-257$.

[46] B. Numbi, X. Xia, Systems optimization model for energy management of a parallel HPGR crushing process, Applied Energy 149 (2015) $133-147$.

[47] D. Setlhaolo, X. Xia, J. Zhang, Optimal scheduling of household appliances for demand response, Electric Power Systems Research 116 (2014) 24 - 28. 